\title{
Nodular Sclerosis Classic Hodgkin Lymphoma, Cellular Phase
}

National Cancer Institute

\section{Source}

National Cancer Institute. Nodular Sclerosis Classic Hodgkin Lymphoma, Cellular Phase. NCI Thesaurus. Code C67171.

A nodular sclerosis Hodgkin lymphoma characterized by the presence of lacunar cells, nodular growth, and the absence of fibrosis. 